\title{
Article \\ Ultra-Low-Reflective, Self-Cleaning Surface by Fabrication Dual-Scale Hierarchical Optical Structures on Silicon
}

\author{
Miaomiao Duan ${ }^{1}\left(\mathbb{D}\right.$, Jingjun $\mathrm{Wu}^{1,2}{ }^{1}$, Yubin Zhang ${ }^{1}$, Ning Zhang ${ }^{1}$, Jun Chen ${ }^{1}$, Zhenhua Lei ${ }^{3}$, Zao Yi ${ }^{3, *(\mathbb{D})}$ \\ and Xin Ye ${ }^{1, *}$ \\ 1 Research Center of Laser Fusion, Materials Science and Technology Department, China Academy of \\ Engineering Physics, Mianyang 621900, China; duanmiaomiao19@gscaep.ac.cn (M.D.); \\ jingjunwu163@njust.edu.cn (J.W.); zhangyubin21@gscaep.ac.cn (Y.Z.); 1162100514@stu.hit.edu.cn (N.Z.); \\ chenjun21@gscaep.ac.cn (J.C.) \\ 2 MIIT Key Laboratory of Advanced Solid Laser, School of Electronic and Optical Engineering, Nanjing \\ University of Science and Technology, Nanjing 210094, China \\ 3 Joint Laboratory for Extreme Conditions Matter Properties, Ministry of Education Key Laboratory of Testing \\ Technology for Manufacturing Process, School of Science, Southwest University of Science and Technology, \\ Mianyang 621010, China; chenxifang1988@yeah.net \\ * Correspondence: yizaomy@swust.edu.cn (Z.Y.); yexin@caep.cn (X.Y.)
}

Citation: Duan, M.; Wu, J.; Zhang, Y.; Zhang, N.; Chen, J.; Lei, Z.; Yi, Z.; Ye, X. Ultra-Low-Reflective, Self-Cleaning Surface by Fabrication Dual-Scale Hierarchical Optical Structures on Silicon. Coatings 2021, 11, 1541. https://doi.org/10.3390/ coatings11121541

Academic Editor: Aomar Hadjadj

Received: 13 November 2021

Accepted: 9 December 2021

Published: 15 December 2021

Publisher's Note: MDPI stays neutral with regard to jurisdictional claims in published maps and institutional affiliations.

Copyright: (c) 2021 by the authors. Licensee MDPI, Basel, Switzerland. This article is an open access article distributed under the terms and conditions of the Creative Commons Attribution (CC BY) license (https:/ / creativecommons.org/licenses/by/ $4.0 /)$.
Abstract: An integrated functional anti-reflective surface is of great significance for optical and optoelectronic devices. Hence, its preparation has attracted great attention from many researchers. This study combined wet alkaline etching approaches and reactive ion etching (RIE) techniques to create a dual-scale hierarchical anti-reflective surface on silicon substrates. The effect of RIE time on surface morphology and optical performance was investigated using multiple characterization forms. The optimal parameters for the fabrication of dual-scale structures by the composite etching process were explored. The silicon surface with a dual-scale structure indicated excellent anti-reflective properties (minimum reflectivity of $0.9 \%$ ) in the 300 to $1100 \mathrm{~nm}$ wavelength range. In addition, the ultra-low reflection characteristic of the surface remained prominent at incident light angles up to $60^{\circ}$. The simulated spectra using the finite difference time domain (FDTD) method agreed with the experimental results. Superhydrophobicity and self-cleaning were also attractive properties of the surface. The functionally integrated surface enables silicon devices to have broad application prospects in solar cells, light emitting diodes (LEDs), photoelectric detectors, and outdoor equipment.

Keywords: ultra-low-reflective; dual-scale structure; reactive ion etching (RIE); wet etching; hydrophobic

\section{Introduction}

Silicon is one of the most abundant materials on Earth and has the characteristics of good chemical stability, no environmental pollution, easy doping, and easy purification [1-5]. It has been widely used in the semiconductor industry. Moreover, silicon is the most promising fundamental material in the microelectronics and solar photovoltaic industries [6-10]. However, with the development of technology, many critical problems have been exposed, such as narrow spectral absorption and high reflectivity. Therefore, it is worthwhile to explore the surface modification technology of silicon materials in depth. The surface of silicon has deficient average absorption in the visible-near-infrared spectral band. Since the last century, researchers have been seeking to improve the absorption coefficient of silicon in the visible-near-infrared spectral band by modifying the surfaces of silicon substrates [11-13]. In particular, the fabrication of micro-nano structures on the silicon surface is a popular route for surface modification [14-21]. For example, pyramidal structures effectively reduce the surface's reflectivity and improve the efficiency of photovoltaic cells, which is attributed to their ability to collect and capture light through internal reflection [22-30]. 
The approaches to constructing micro-nano structures on silicon substrates have been categorized into two species: wet etching and dry etching. One of the conventional operations for wet etching is the anisotropic etching of silicon using alkaline chemicals (potassium hydroxide/sodium hydroxide). This method has the advantages of low cost, simple equipment, easy observation, easy operation, and easy preparation of large areas [2,31-33]. Dry etching uses an ion source with specific energy to bombard the substrate material and causes it to peel to achieve etching. With continuous development, dry etching has led to a variety of processes, such as reactive ion etching (RIE) [34-37], the inductively coupled plasma etching (ICP) process [38-40], the ion beam etching process, and deep reactive ion etching (DRIE) [41]. RIE is an etching method that produces both physical and chemical effects. The technique can be operated at room temperature and has the advantage of fast etching speed and high precision.

Here, we developed an ultra-low-reflectivity surface with unique wetting properties by combining wet etching methods with RIE techniques. The effect of RIE time on silicon surface morphology and optical properties with micro-nano dual-scale hierarchical structures was investigated. The optimal technical parameters for the fabrication of dual-scale structures by the RIE technique combined with the wet etching process were obtained. The optical property of the surface was simulated using the finite difference in the time domain (FDTD) method. Hydrophobicity and self-cleaning are also attractive properties of the surface. We also briefly compared this work with those recently reported, as shown in Table 1. The functionally integrated surface enables silicon devices to have broad application prospects in solar cells, LEDs, photoelectric detectors, and outdoor equipment.

Table 1. Comparison of this work with recently reported work.

\begin{tabular}{cccc}
\hline $\begin{array}{c}\text { Minimum } \\
\text { Reflectance }\end{array}$ & Wavelength Range & Wettability & References \\
\hline $0.92 \%$ & $300 \mathrm{~nm} \sim 1100 \mathrm{~nm}$ & super-hydrophobic & this work \\
$1.27 \%$ & $300 \mathrm{~nm} \sim 800 \mathrm{~nm}$ & hydrophobic & {$[2]$} \\
$2.5 \%$ & $300 \mathrm{~nm} \sim 1200 \mathrm{~nm}$ & uncharacterized & {$[28]$} \\
$\sim 5 \%$ & $200 \mathrm{~nm} \sim 1100 \mathrm{~nm}$ & super-hydrophobic & {$[42]$} \\
$\sim 1 \%$ & $350 \mathrm{~nm} \sim 1100 \mathrm{~nm}$ & super-hydrophilic & {$[43]$} \\
$1.3 \%$ & $300 \mathrm{~nm} \sim 1100 \mathrm{~nm}$ & uncharacterized & {$[44]$} \\
\hline
\end{tabular}

\section{Experimental Section}

\subsection{Materials}

Silicon wafer $\left(20 \times 20 \times 5 \mathrm{~mm}^{3}\right.$, the resistivity of $1 \sim 10 \Omega \mathrm{cm}$, p-type, single-sided polished), isopropyl alcohol (IPA, $A R \geq 99.5 \%$ ), potassium hydroxide $(\mathrm{KOH})$, hydrofluoric acid (HF), anhydrous ethanol, acetone, deionized water, trifluoromethane $\left(\mathrm{CHF}_{3}\right)$, sulfur hexafluoride $\left(\mathrm{SF}_{6}\right)$, and helium $(\mathrm{He})$.

\subsection{Fabrication of Dual-Scale Hierarchical Micro-Nano-Structured Optical Surface}

The silicon wafers were first ultrasonically cleaned using, in order, acetone, anhydrous ethanol, and deionized water. The purpose was to remove contaminants such as oil, particles, and metals left on the surface during manufacturing. Each solvent was cleaned in two cycles, each cycle lasting $10 \mathrm{~min}$. The cleaned wafers were placed in a certain amount of HF to remove the oxide layer on the surface. The reaction time was $1 \mathrm{~min}$, and the control temperature was $70^{\circ} \mathrm{C}$. The wafers with the oxide layer removed were wet-etched in a mixture of $\mathrm{KOH}$ and isopropanol for $15 \mathrm{~min}$ at a controlled temperature of $80^{\circ} \mathrm{C}$. After the wet reaction, the samples were washed with deionized water and blown dry with nitrogen.

Further to optimize the sample surface, the wet-etched samples were resurfaced by RIE. The samples were placed in a vacuum chamber, and the radio frequency (RF) power was set to $300 \mathrm{~W}$. The gas reactant was a mixture containing $\mathrm{CHF}_{3} / \mathrm{SF}_{6} / \mathrm{He}$. During the etching process, the chamber pressure was maintained at $5 \mathrm{~Pa}$ and the etching time was 
5 25 min. Ultimately, exotic dual-scale structures were formed on the silicon surface after two etchings.

\subsection{Performance Characterization}

The morphology of the silicon wafers was analyzed by scanning electron microscopy (SEM, ZEISS FESEM ULTRA 55, Carl zeissNTS GmbH, Jena, Germany). Reflectance measurements at 300 1100 nm were performed using a UV-Vis-NIR spectrophotometer (PerkinElmer Lambda 950, PerkinElmer, Waltham, MA, USA). The surface wettability of the samples was characterized using a contact angle tester (JC2000C, Shanghai Zhongchen Digital Technology Co., Shanghai, China).

\section{Results and Discussion}

The schematic diagram in Figure 1 briefly illustrates the fabrication of the surface with micro-nano dual-scale structures. First, the silicon wafers $<100>$ were anisotropically etched with alkaline solvent. The essence of the chemical reaction is the reaction between $\mathrm{Si}$ and $\mathrm{OH}^{-}$:

$$
\mathrm{Si}+2 \mathrm{OH}^{-}+4 \mathrm{H}_{2} \mathrm{O} \rightarrow \mathrm{Si}(\mathrm{OH})_{6}^{2-}
$$

(a)

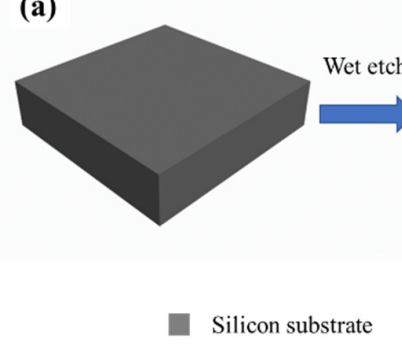

(b)
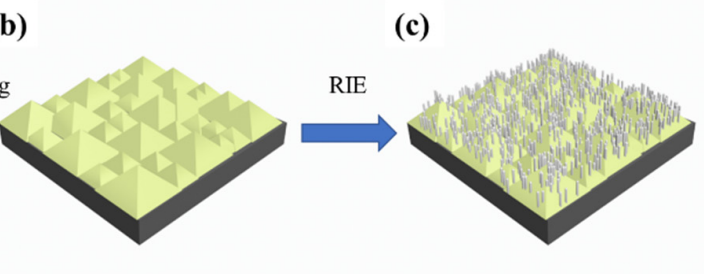

Figure 1. The process of fabrication of dual-scale hierarchical optical structures on silicon. (a) Unetched silicon wafer (b) Wet etched silicon wafer (c) Further RIE etched wafer.

The generated silicon particles immediately afterward can undergo a complexation reaction with IPA, as shown in the following equation:

$$
\mathrm{Si}(\mathrm{OH})_{6}^{2-}+6\left(\mathrm{CH}_{3}\right)_{2} \mathrm{CHOH} \rightarrow\left[\mathrm{Si}\left(\mathrm{OC}_{3} \mathrm{H}_{7}\right)_{6}\right]^{2-}+6 \mathrm{H}_{2} \mathrm{O}
$$

The complexation reaction products were proven to be highly soluble in water. Therefore, the anisotropic corrosion reaction of silicon wafers can be carried out continuously, leading to the final formation of the micro-scale pointed cone shape of the pyramid structure. However, the silicon surface properties of micro-scale pyramids have not yet fully achieved the goal of ultra-low reflection. The surface needs to be further optimized.

The next step was to execute the RIE of the above micron pyramid structure. During etching with $\mathrm{CHF}_{3} / \mathrm{SF}_{6} / \mathrm{He}$ plasma, there was constant competition between reactive fluorine ions $\left(\mathrm{CF}_{\mathrm{x}}+, \mathrm{SF}_{\mathrm{x}}+\right)$ and passivated fluorocarbons $\left(\mathrm{CF}_{\mathrm{x}}\right) . \mathrm{SF}_{6}$ generates a glow discharge at a specific voltage and forms fluorine radicals $(\mathrm{F} *)$, which immediately react with silicon atoms on the sample surface to form volatile gas products. The chemical reaction equations are:

$$
\begin{gathered}
\mathrm{SF}_{6}+\mathrm{e}^{-} \rightarrow \mathrm{SF}_{5}^{+}+\mathrm{F} *+2 \mathrm{e}^{-} \\
\mathrm{Si}+4 \mathrm{~F} * \rightarrow \mathrm{SiF}_{4} \uparrow
\end{gathered}
$$

Under suitable RIE etching conditions, $\mathrm{CF}_{\mathrm{x}}$ was randomly deposited on the surface to act as a mask to prevent etching. Therefore, in the RIE, two processes co-occur: fluorocarbon deposition and etching. Helium was added for two primary purposes: energy transfer and intermolecular spacing reduction. The balance of etching and fluorocarbon deposition can be used to fabricate nano-scale structures. The effective combination of wet etching and reactive ion etching produced a micro-nano dual-scale surface. 


\subsection{Fabrication of Micro-Scale Pyramidal Structure}

The morphological structure of the silicon wafers after wet etching was observed using SEM. Figure $2 \mathrm{a}$ and the inset show the sample's top and side-view SEM images after anisotropic alkaline etching, respectively. It can be noticed that micro-scale structures with distinctive characteristics are presented on the surface of the bare silicon wafer. Viewed as a whole, the micro-scale structures are compactly arranged, and the substrate is thoroughly covered. Individually, the angles are well-defined and exhibit a conspicuous pyramidal feature. Figure $2 b$ compares the reflection spectra of the bare silicon wafer and the silicon wafers equipped with micro-scale structures in the wavelength range of $300 \sim 1100 \mathrm{~nm}$. Wet etching can effectively reduce the reflectance in the broadband wavelength. The average reflectance is reduced by $23.72 \%$. From the perspective of geometrical optics, when the incident light arrives at the surface of a bare silicon wafer, there is only one reflection, and the incident light is absorbed once. However, at least two reflections occur when the incident light reaches a surface with a micron pyramidal structure, and the sunlight is absorbed at least twice. The wet etching approach to fabricate micro-scale anti-reflective structures provided a favorable basis for the subsequent preparation of dual-scale forms.
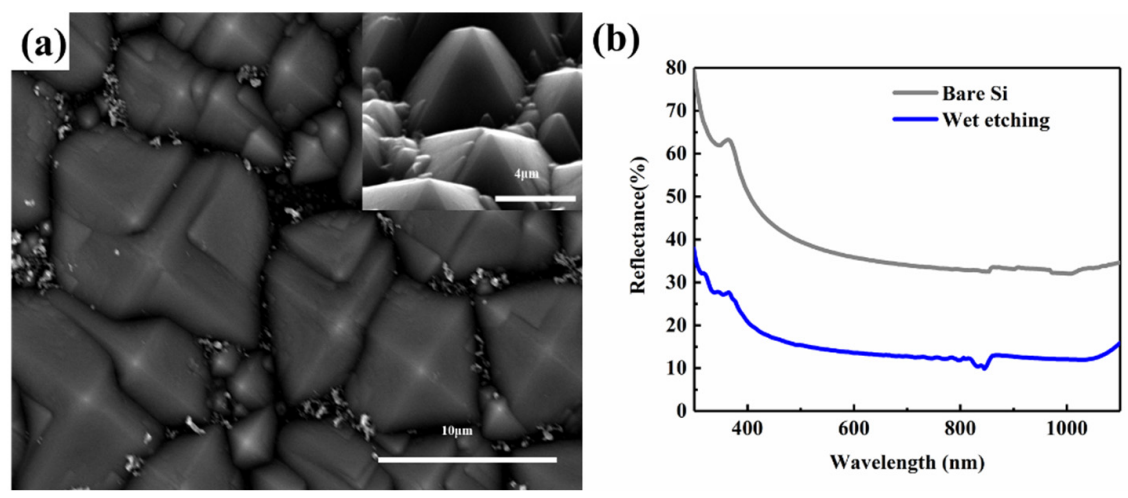

Figure 2. (a) SEM image of the silicon wafer after wet etching. (b) Reflectance spectra of the bare wafer and wet etched wafer.

\subsection{Fabrication of Dual-Scale Hierarchical Structures}

We obtained dual-scale structures with excellent anti-reflective properties by further sculpting the nano-scale structure on the micro-scale structure through RIE. During RIE, the etching time directly affects the density and size of the nanostructure, which ultimately affects the anti-reflective properties of the silicon surface. To explore the effect of RIE time on the anti-reflective properties of the silicon surface more quickly, we first performed the RIE operation on bare silicon wafers and characterized the morphology and reflection spectra of different samples.

Figure 3 shows the surface morphology and anti-reflective properties of the sample treated by one-step reactive ion etching solely, and the experimental parameters are detailed in Table 2. Figure 3a-d show the SEM images of the samples at RIE times of $10 \mathrm{~min}, 15 \mathrm{~min}$, $20 \mathrm{~min}$, and $25 \mathrm{~min}$, respectively. As shown in Figure 3a, when the reactive ion etching process lasted for $10 \mathrm{~min}$, the entire surface of the silicon wafer was almost uniformly distributed by fluorocarbons. At the same time, some nanostructures appear, which are sparsely arranged with large average spacing. As the etching time increases to $15 \mathrm{~min}$, the number of new nanodots on the surface increases and the nanostructures become tightly arranged, as demonstrated in Figure 3b. However, the strength between the fluorocarbon deposition effect and the etching effect changes as the time increases during the reactive ion etching process. When the reaction time is extended to $20 \mathrm{~min}$, the etching effect is stronger than the fluorocarbon deposition effect. Thus, the size of the nanostructures in Figure $3 c$ is larger than that in Figure 3b. When the etching time is $25 \mathrm{~min}$, it can be noticed from Figure $3 \mathrm{~d}$ that the density of the nanostructures becomes smaller and the size becomes larger, and these changes are due to the annexation effect between adjacent structures. 

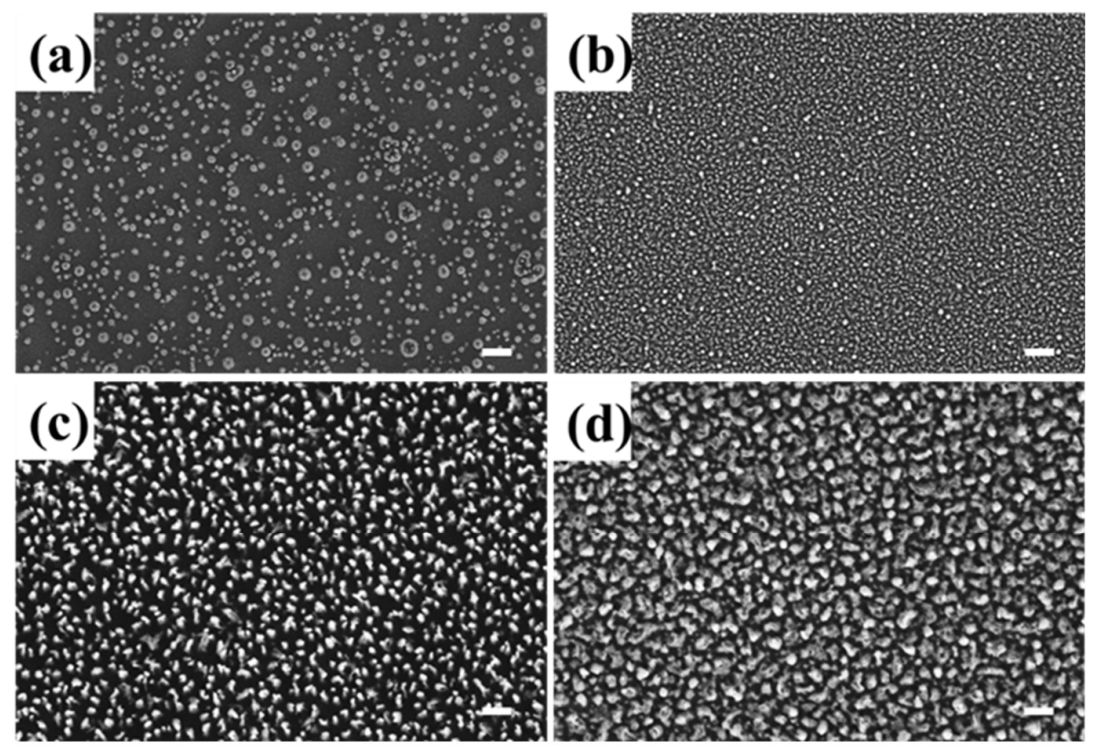

(e)

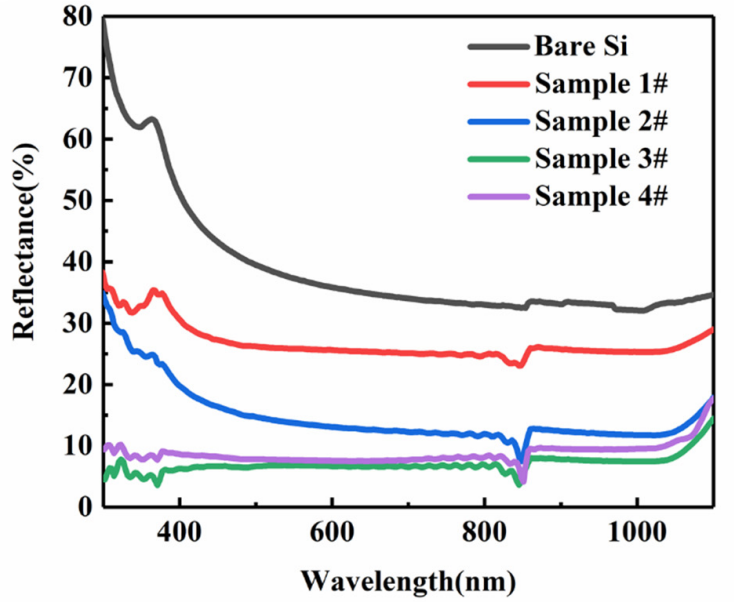

(f)

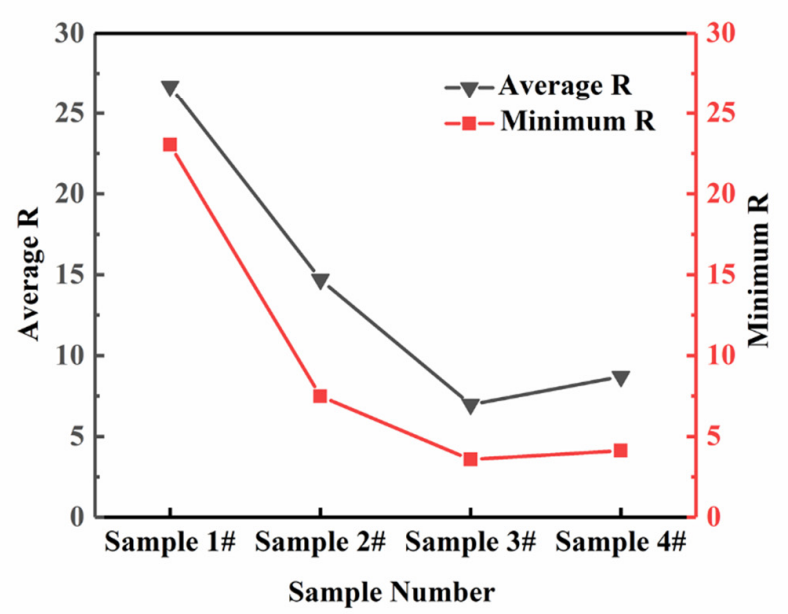

Figure 3. RIE with different etching times: SEM of samples (a) $10 \mathrm{~min}$, (b) $15 \mathrm{~min}$, (c) $20 \mathrm{~min}$, (d) 25 min; (e) reflectance spectra of different samples; (f) average $\mathrm{R}$ and minimum $\mathrm{R}$ plot for samples with different RIE etching times. Scale bars $1 \mu \mathrm{m}$. 
Table 2. Samples etched with different RIE times.

\begin{tabular}{lcccc}
\hline No. & Etching Time (min) & Gas Ratio $\left(\mathrm{SF}_{6}: \mathrm{CHF}_{3}: \mathrm{He} \mathbf{s c c m}\right)$ & Pressure (Pa) & Power (W) \\
\hline $1 \#$ & 10 & & & \\
$2 \#$ & 15 & $50: 30: 50$ & 5 & 300 \\
$3 \#$ & 20 & & & \\
$4 \#$ & 25 & & & \\
\hline
\end{tabular}

The samples treated under different conditions differed not only in morphology but also in anti-reflective properties. As shown in Figure 3e,f, the average reflectance decreased by approximately $12 \%$ when the etching time was increased from 10 to $15 \mathrm{~min}$. After 20 min of RIE, the average reflectance of the sample again decreased by $7.73 \%$. When the etching time lasted for $25 \mathrm{~min}$, the average reflectance increased by $1.72 \%$. The surface of the sample after $20 \mathrm{~min}$ of etching had the lowest reflectance of $3.57 \%$. Overall, the average reflectance and the minimum reflectance show a trend of decreasing and then increasing with prolongation of the etching time, which is consistent with the pattern of structural changes.

The RIE time parameter altered the surface structure and had an impact on performance. We repeated RIE on the wet-etched samples to create dual-scale micro-nano hierarchical structures on the silicon based on the above experimental results. Figure $4 a-d$ show the SEM of the sample surface under different combination etching parameters. The details of the combination process parameters are shown in Table 3. Figure $4 a-d$ correspond to RIE times of $10 \mathrm{~min}, 15 \mathrm{~min}, 20 \mathrm{~min}$, and $25 \mathrm{~min}$, respectively. The rough morphology emerged during the etching process as the fluorocarbon was further deposited on the wet-etched micrometer pyramidal structure. RIE was treated for $10 \mathrm{~min}$, and the micro-scale pyramidal structure from the previous wet etching step in Figure 4a had a distinctive structure with well-defined angles. The nano-scale structures obtained by RIE were uniformly and densely distributed. With the increase in etching time, the micro-scale pyramidal structure of the whole surface did not change significantly; however, the nano-scale structure became denser and larger than when treated for $10 \mathrm{~min}$. The distance between the nano-scale structures was slightly larger than the diameter of the nanostructures. These details are shown in Figure 4b. Continuing to deepen the etching, the pyramid shape was still evident, and the nano-scale structures were larger and more uniform in size. Figure $4 \mathrm{c}$ shows the top view of the SEM at an etching time of $20 \mathrm{~min}$, while Figure 4e shows the corresponding cross-sectional SEM image, from which we can visualize the dual-scale feature of the structure. However, after the etching time was greater than $20 \mathrm{~min}$, the etching deepened, the adjacent nano-scale structures were aggregated, and the outline of the micro-scale pyramid was destroyed and became softened. 

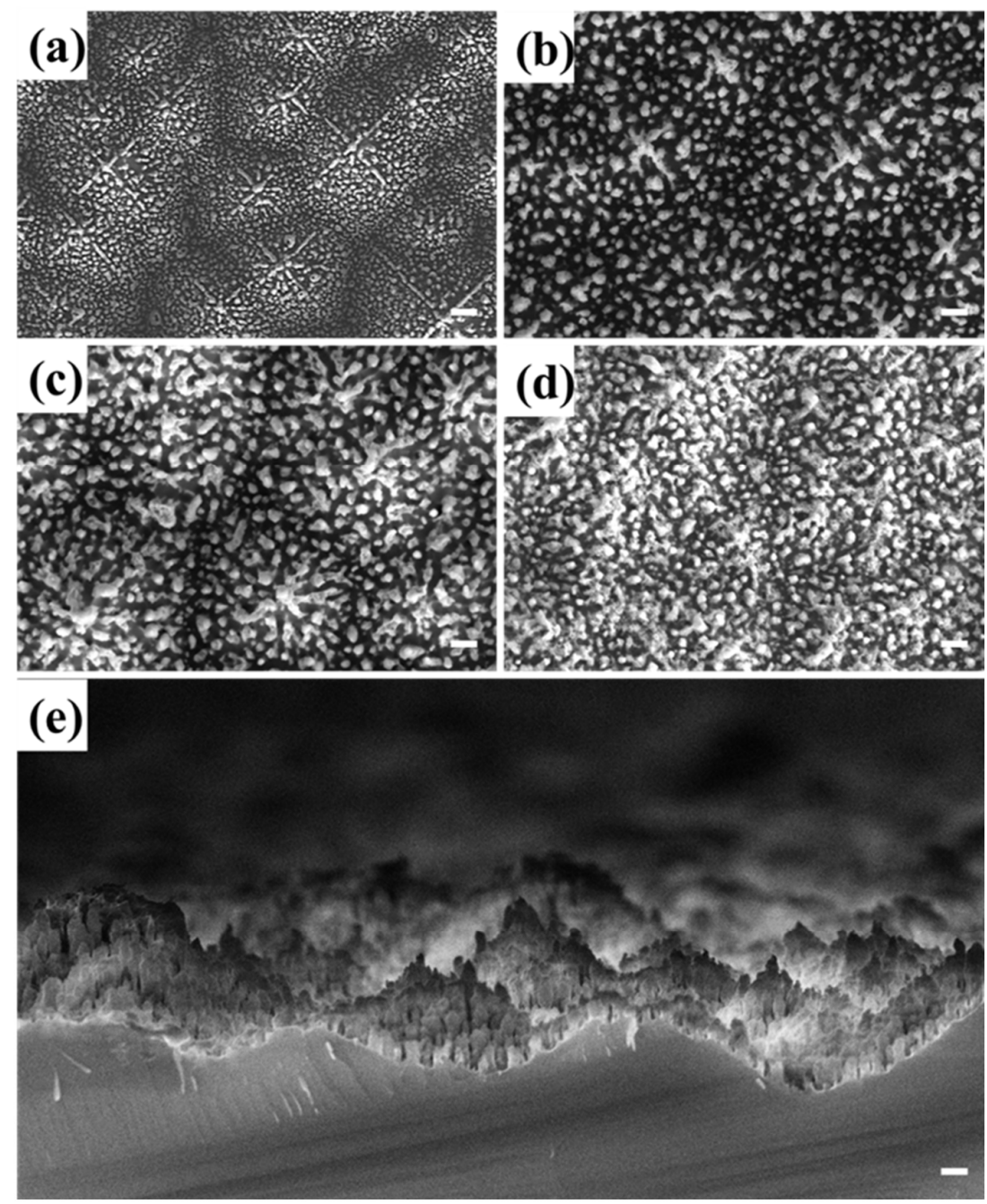

(f)

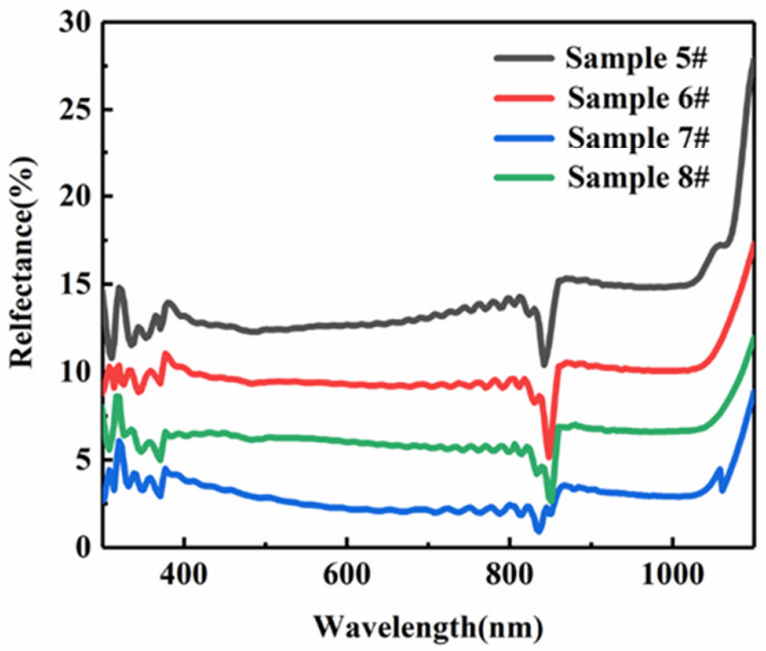

Figure 4. Cont. 
(g)

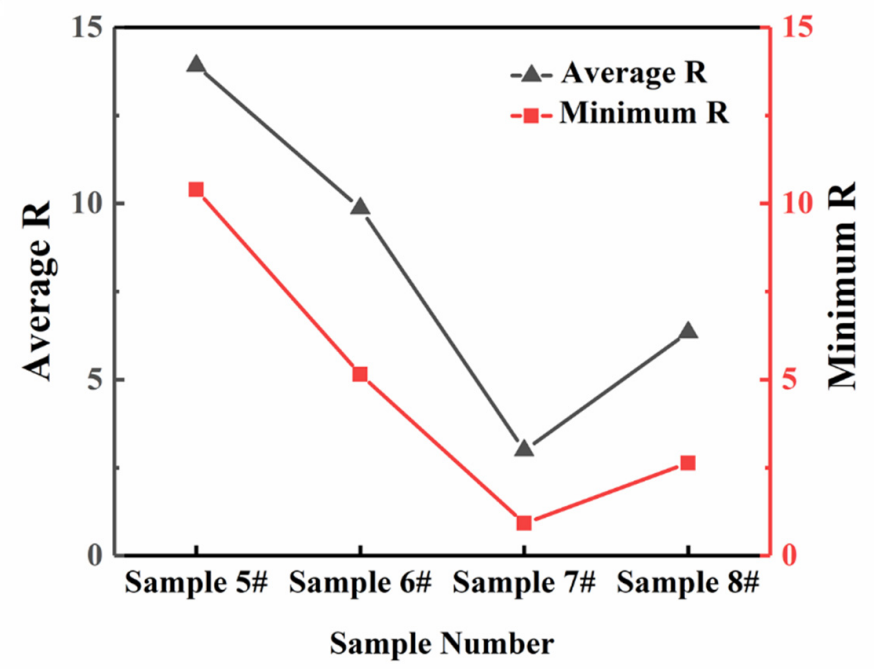

Figure 4. Morphology and reflectance spectral information of dual-scale structures: SEM of samples with different RIE times (a) $10 \mathrm{~min}$, (b) $15 \mathrm{~min}$, (c) $20 \mathrm{~min}$, (d) $25 \mathrm{~min}$; (e) SEM cross-sectional view of sample with optimal etching parameters, scale bars $1 \mu \mathrm{m}$; (f) reflectance spectra of different samples; (g) average $\mathrm{R}$ and minimum $\mathrm{R}$ plot for different samples.

Table 3. Samples etched by wet etching and at different RIE times.

\begin{tabular}{cccccc}
\hline No. & $\begin{array}{c}\text { Wet } \\
\text { Etching }\end{array}$ & $\begin{array}{c}\text { Etching } \\
\text { Time (min) }\end{array}$ & $\begin{array}{c}\text { Gas Ratio } \\
\left(\mathrm{SF}_{\mathbf{6}}: \mathrm{CHF}_{3}: \mathrm{He} \mathrm{sccm}\right)\end{array}$ & $\begin{array}{c}\text { Pressure } \\
(\mathbf{P a})\end{array}$ & $\begin{array}{c}\text { Power } \\
(\mathbf{W})\end{array}$ \\
\hline $5 \#$ & $\mathrm{KOH}(500 \mathrm{~mL})+$ & 10 & & & \\
$6 \#$ & $\mathrm{IPA}(100 \mathrm{~mL})$ & 15 & $50: 30: 50$ & 5 & 300 \\
$7 \#$ & $15 \mathrm{~min}$ & 20 & & & \\
$8 \#$ & $80^{\circ} \mathrm{C}$ & 25 & & & \\
\hline
\end{tabular}

The reflectance spectral data of the samples for various combined etching conditions are given in Figure 4f,g. When the etching time was extended from $10 \mathrm{~min}$ to $20 \mathrm{~min}$, the dense and increasing nano-scale structures played a role, and the reflectivity decreased by $10.92 \%$ on average. However, when the etching time exceeded $20 \mathrm{~min}$, the effect of the micro-scale pyramids in reducing reflection was eliminated, and the reflectivity increased by an average of $3.35 \%$. The lowest reflectivity of $0.92 \%$ was achieved when the etching time was $20 \mathrm{~min}$, which was the optimal time parameter.

Based on the above experimental results, we summarized the basic mechanism of the effect of etching time on the reflectivity of the dual-scale structure. The RIE process was a process in which two reactions, fluorocarbon deposition and etching, were carried out simultaneously and competed. The relative intensities of the deposition and etching processes were in the process of change with different etching times. When the deposition of fluorocarbon dominated, the nanodots in the structure increased, and the density of the nanostructure changed more significantly. While when the etching process played a major role, the size of the nanostructure changed more significantly. It was precisely the variability of these two processes that gave rise to the variability of the dual-scale structure with the etching time, and ultimately to the different anti-reflective properties.

\subsection{Optical Properties of Surfaces with Dual-Scale Hierarchical Structures}

Photographs of the samples treated with the different etching processes were captured under natural light. Figure 5a can be described as follows. The original silicon wafer on the far left intensely reflected natural light and could mirror clear text. Next was the silicon wafer etched by wet etching. The silicon wafer etched by one-step RIE was relegated to the third position, and the silicon wafer with dual-scale structures prepared by the composite 
process was placed on the far right, and it was clearly the darkest of the four samples, with the lowest reflectivity. The reflectance spectra corresponding to the four physical samples are given in Figure 5b. The silicon wafer's high refractive index results in an average surface reflectance of more than $35 \%$. After wet etching, the average reflectivity of the silicon wafer surface was reduced by nearly $61 \%$, with a minimum reflectivity of $9.81 \%$. Further, the reflectance reduction of the sample after one-step dry etching was also well-demonstrated. The average reflectance was $6.97 \%$ in the $300 \sim 1100 \mathrm{~nm}$ band. The composite etched samples had the finest anti-reflective properties. The average reflectance in the UV-Vis-NIR band was $2.99 \%$, and the lowest reflectance was $0.92 \%$. The dual-scale structure derived from both wet and dry etching processes, which traps the light, is intrinsic to the low reflectivity performance.

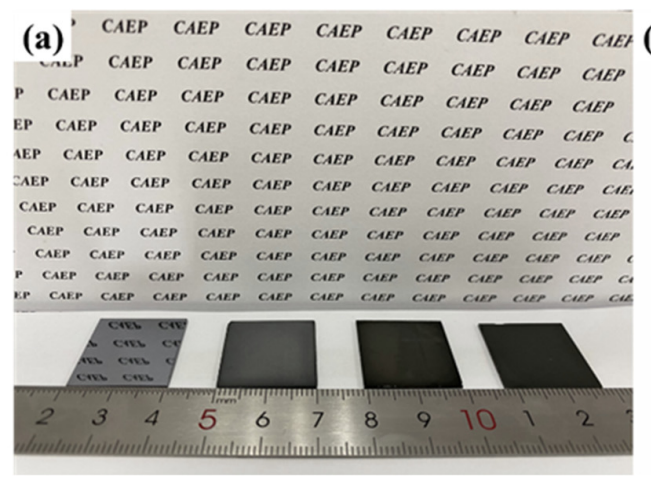

(b)

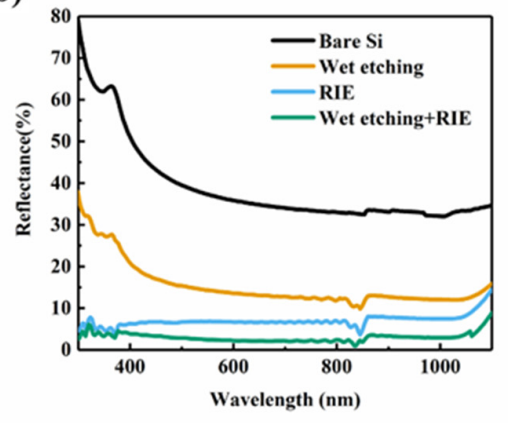

Figure 5. (a) Photographs of the samples treated by different etching processes were captured under natural light. (b) Reflectance spectra corresponding to the samples in Figure 5a.

Thus, we theoretically simulated the anti-reflection properties of the dual-scale hierarchical structure using the commercial software FDTD version 2019. First, the whole surface was divided into two layers: the lower layer was the silicon substrate layer, and the upper layer was the etched dual-scale structure. Among them, the dimensional parameters of the dual-scale structure were set as a micron pyramid with a height and width of $\mathrm{L}=5 \mu \mathrm{m}$, and the nano-scale structure was a cone with a variable bottom diameter $(\mathrm{d}=50 \mathrm{~nm} \sim 200 \mathrm{~nm})$ and height $(\mathrm{h}=450 \mathrm{~nm} \sim 700 \mathrm{~nm}$ ). It was noticed that the micron-scale pyramids in the simulation model were arranged periodically, while the uppermost nanoscale structures were randomly distributed. Material settings for pyramid structure, nanoscale structure, and substrate structure were set to "Si (Silicon) Palik". The filling medium between each different structure was air. The incident light source was a plane-wave light source with a wavelength band of 300 1100 $\mathrm{nm}$ and a Z-axis negative direction. The grid size was set to: $\mathrm{dx}=5 \mathrm{~nm}, \mathrm{dy}=5 \mathrm{~nm}, \mathrm{dz}=10 \mathrm{~nm}$. Regarding the boundary conditions, the $X$ and $Y$ directions were set to "Bloch", and the $\mathrm{Z}$ direction was set to "PML". The reflectivity detector was placed at the boundary of the simulation area and the light source. Figure 6a shows the schematic diagram of the simulation model. After data comparison, the reflectance and absorption data of the simulation model with dimensions $(\mathrm{h}=600 \mathrm{~nm}, \mathrm{~d}=60 \mathrm{~nm}$ ) were close to the measured results of the dual-scale hierarchical structure shown in Figure 4e. The comparison results are shown in Figure $6 c, d$, respectively. Figure $6 \mathrm{~b}$ displays the electric field intensity map of the wavelength at $590 \mathrm{~nm}$ (this wavelength corresponds to the lowest reflectivity). All in all, it has been demonstrated both theoretically and experimentally that the prepared dual-scale hierarchical structure was a low-reflection and high-absorption structure. 


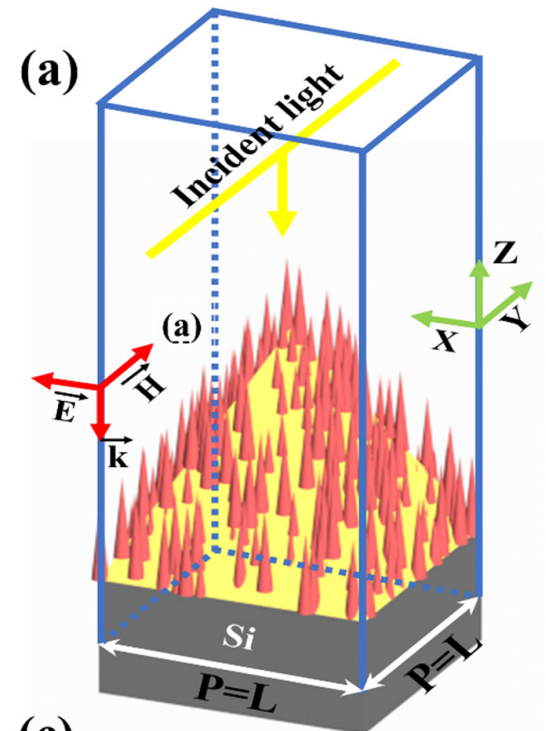

(b)

(c)

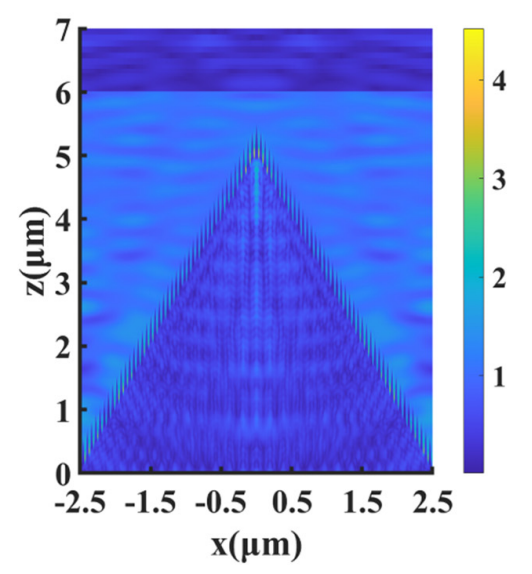

(d)
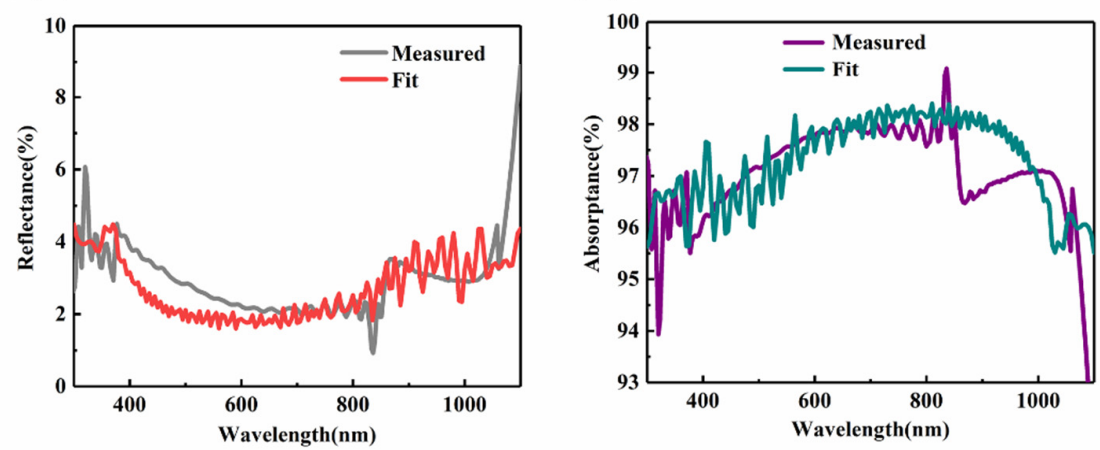

Figure 6. (a) Schematic diagram of simulation model; (b) the electric field intensity map of the XZ plane $\lambda=590 \mathrm{~nm}$ (this wavelength corresponds to the lowest reflectivity); (c) simulation and experimental reflection spectra of dual-scale micro-nano hierarchical structure; (d) simulation and experimental absorption spectra of dual-scale micro-nano hierarchical structure.

The ultra-low reflection of the surface with dual-scale hierarchical structures occurred not only in a wide wavelength range from 300 to $1100 \mathrm{~nm}$ but also at large angular incidence of the light. Figure 7 shows the specular reflectance of the hierarchical structure for angles of incidence varying from $0^{\circ}$ to $75^{\circ}$. The specular reflectance of these optimized dual-scale structures remained below $1 \%$ even at angles as high as $60^{\circ}$. The high tolerance to the angle of incident light will facilitate the maximization of light absorption by solar cells without actively tracking sunlight. 


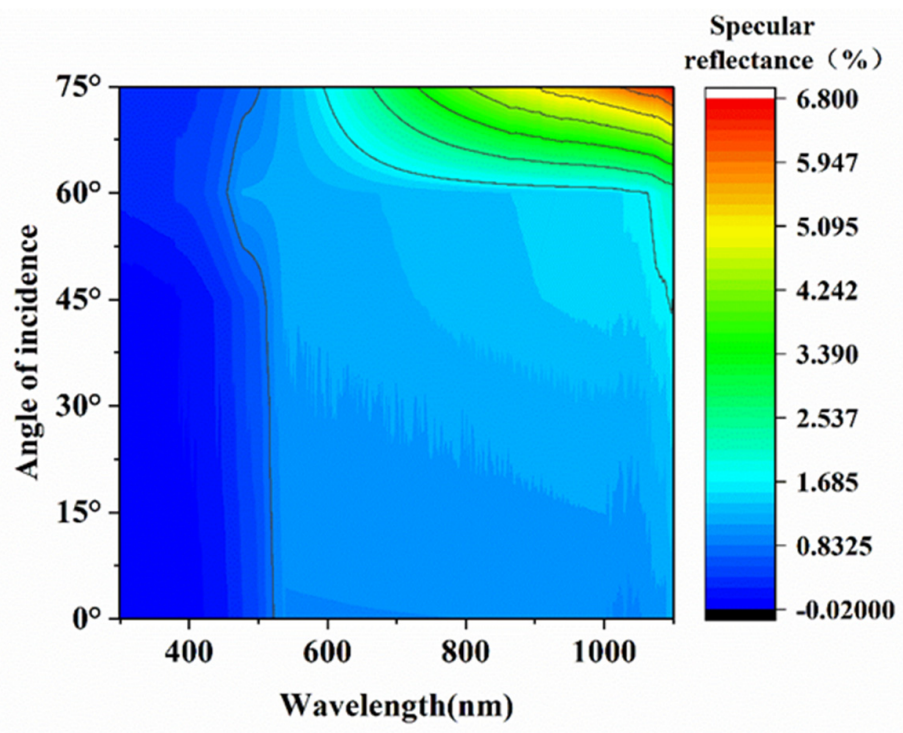

Figure 7. Contour plots of specular reflectance of dual-scale micro-nano hierarchical structures at different angles of incidence.

\subsection{Wettability of Surfaces with Dual-Scale Hierarchical Structures}

The superhydrophobicity of silicon devices is of great importance in various practical applications owing to their fascinating self-cleaning properties. To evaluate the wettability of the dual-scale hierarchical structured silicon surface, water contact angle (WCA) measurements were carried out. Figure 8 a shows the water contact angle measurement of $105.54^{\circ}$ for the sample etched by wet etching only, which corresponds to the surface of a micro-scale pyramidal structure. Figure $8 \mathrm{~b}$ shows the WCA measurement of $152.31^{\circ}$ for the sample etched by wet etching and then by RIE. The test results clearly show that the surface with the micro-nano dual-scale structure exhibits superhydrophobicity. In practice, contaminants and dust adhering to a superhydrophobic surface are easily washed off by water, so the surface exhibits self-cleaning properties.

(a)

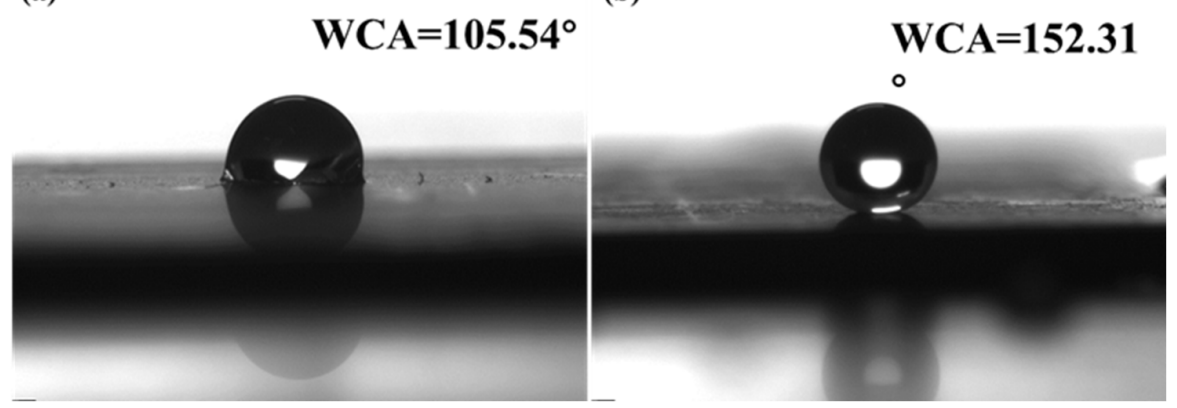

Figure 8. WCA test results of different samples: (a) wet-etched, (b) wet etching and RIE combined.

\section{Conclusions}

In conclusion, dual-scale anti-reflective structures were prepared by a combination of the wet etching process and RIE technology. The anti-reflection performance of the surface was optimal when the RIE time was 20 min under the conditions of invariable gas flow rate and RF power. The micro-scale pyramidal and the nano-scale structures were perfectly combined in scale and position, enabling the silicon device's surface to absorb light from all directions. Silicon surfaces with a dual-scale hierarchical structure exhibited excellent anti-reflection properties in the wide wavelength range of 300 to $1100 \mathrm{~nm}$, with a minimum reflectance of $0.92 \%$. In particular, the ultra-low anti-reflection property of the surface was highly tolerant to the incident light angle, which was still apparent at incident 
light angles as high as $60^{\circ}$. Simultaneously, due to the existence of the dual-scale structure, the silicon wafer surface acquired superhydrophobic properties, and the whole device had the capability of self-cleaning. This work demonstrates that the combination of wet etching and RIE techniques to prepare such dual-scale structures is standard and feasible. It provides an effective solution for large area preparation of integrated functional silicon devices. However, the surface mechanical properties of devices with dual-scale structures should be further improved.

Author Contributions: Conceptualization, M.D.; methodology, Z.Y. and X.Y.; software, M.D., N.Z., J.C. and Z.L.; validation, N.Z., J.C. and Z.L.; investigation, Y.Z.; data curation, N.Z.; writing-original draft preparation, M.D.; writing - review and editing, M.D. and J.W.; visualization, M.D. and Y.Z.; supervision, Z.Y. and X.Y.; project administration, X.Y.; funding acquisition, X.Y. All authors have read and agreed to the published version of the manuscript.

Funding: The work is supported by the Innovation and Development Foundation of China Academy of Engineering Physics (grant number: CX20200021), and the Scientific Research Fund of SiChuan Provincial Science and Technology Department (grant number: 2020YJ0137).

Institutional Review Board Statement: Not applicable.

Informed Consent Statement: Not applicable.

Data Availability Statement: The study did not report any data.

Conflicts of Interest: The authors declare no conflict of interest.

\section{References}

1. Ye, X.; Huang, J.; Ni, R.F.; Yi, Z.; Zheng, W.G. Broadband antireflection and self-cleaning random grass structure on silicon. J. Optoelectron. Adv. Mater. 2015, 17, 192-197.

2. Zeng, Y.; Fan, X.; Chen, J.; He, S.; Yi, Z.; Ye, X.; Yi, Y. Preparation of composite micro/nano structure on the silicon surface by reactive ion etching: Enhanced anti-reflective and hydrophobic properties. Superlattices Microstruct. 2018, 117, 144-154. [CrossRef]

3. Yang, C.; Jing, X.; Wang, F.; Ehmann, K.F.; Tian, Y.; Pu, Z. Fabrication of controllable wettability of crystalline silicon surfaces by laser surface texturing and silanization. Appl. Surf. Sci. 2019, 497, 143805. [CrossRef]

4. Liu, S.; Niu, X.; Shan, W.; Lu, W.; Zheng, J.; Li, Y.; Duan, H.; Quan, W.; Han, W.; Wronski, C.R. Improvement of conversion efficiency of multicrystalline silicon solar cells by incorporating reactive ion etching texturing. Sol. Energy Mater. Sol. Cells 2014, 127, 21-26. [CrossRef]

5. Chen, W.H.; Hong, C.N. 0.76\% absolute efficiency increase for screen-printed multicrystalline silicon solar cells with nanostructures by reactive ion etching. Sol. Energy Mater. Sol. Cells 2016, 157, 48-54. [CrossRef]

6. Rajkanan, K.; Singh, R.; Shewchun, J. Absorption coefficient of silicon for solar cell calculations-ScienceDirect. Solid-State Electron. 1979, 22, 793-795. [CrossRef]

7. Saga, T. Advances in crystalline silicon solar cell technology for industrial mass production. Npg Asia Mater. 2010, 2, 96-102. [CrossRef]

8. Huang, Z.; Carey, J.E.; Liu, M.; Guo, X.; Mazur, E.; Campbell, J.C. Microstructured silicon photodetector. Appl. Phys. Lett. 2006, 89, 516. [CrossRef]

9. Beam, J.C.; Leblanc, G.; Gizzie, E.A.; Ivanov, B.L.; Needell, D.R.; Shearer, M.J.; Jennings, G.K.; Lukehart, C.M.; Cliffel, D.E. Construction of a Semiconductor-Biological Interface for Solar Energy Conversion: P-Doped Silicon/Photosystem I/Zinc Oxide. Langmuir Acs J. Surf. Colloids 2015, 31, 10002-10007. [CrossRef]

10. Lee, C.; Bae, S.Y.; Mobasser, S.; Manohara, H. A novel silicon nanotips antireflection surface for the micro sun sensor. Nano Lett. 2005, 5, 2438-2442. [CrossRef]

11. Zhang, D.; Ren, W.; Zhu, Z.; Zhang, H.; Liu, B.; Shi, W.; Qin, X.; Cheng, C. Highly-ordered silicon inverted nanocone arrays with broadband light antireflectance. Nanoscale Res. Lett. 2015, 10, 9. [CrossRef]

12. Chang, L.; Qiu, R.; Wen, C.; Li, Z.; Hu, S. Microstructuring and doping of silicon with nanosecond laser pulses. Appl. Surf. Sci. 2012, 258, 8002-8007. [CrossRef]

13. Davidsen, R.S.; Li, H.; To, A.; Wang, X.; Han, A.; An, J.; Colwell, J.; Chan, C.; Wenham, A.; Schmidt, M.S. Black silicon laser-doped selective emitter solar cell with 18.1\% efficiency. Sol. Energy Mater. Sol. Cells 2016, 144, 740-747. [CrossRef]

14. Cai, J.; Qi, L. Recent advances in antireflective surfaces based on nanostructure arrays. Mater. Horiz. 2015, 2, 37-53. [CrossRef]

15. Leon, J.J.D.; Hiszpanski, A.M.; Bond, T.C.; Kuntz, J.D. Design Rules for Tailoring Antireflection Properties of Hierarchical Optical Structures. Adv. Opt. Mater. 2017, 5, 1700080. [CrossRef]

16. Li, B.; Niu, G.; Yi, Y.; Zhou, X.W.; Liu, X.D.; Sun, L.X.; Wang, C.Y. Antireflection subwavelength structures based on silicon nanowires arrays fabricated by metal-assisted chemical etching. Superlattices Microstruct. 2017, 111, 57-64. [CrossRef] 
17. Deng, Z.; Yang, Q.; Chen, F.; Meng, X.; Bian, H.; Yong, J.; Shan, C.; Hou, X. Fabrication of large-area concave microlens array on silicon by femtosecond laser micromachining. Opt. Lett. 2015, 40, 1928-1931. [CrossRef] [PubMed]

18. Dawood, M.K.; Liew, T.H.; Lianto, P.; Hong, M.H.; Tripathy, S.; Thong, J.; Choi, W.K. Interference lithographically defined and catalytically etched, large-area silicon nanocones from nanowires. Nanotechnology 2010, 21, 205305. [CrossRef] [PubMed]

19. Zhang, Z.; Wang, Z.; Wang, D.; Ding, Y. Periodic antireflection surface structure fabricated on silicon by four-beam laser interference lithography. J. Laser Appl. 2013, 26, 012010. [CrossRef]

20. Wen, C.; Li, X.; He, X.; Duan, X.; Hu, S. Microstructuring and doping of monocrystalline silicon with femtosecond and nanosecond laser pulses. High Power Laser Part. Beams 2015, 27, 228-234. [CrossRef]

21. Liu, Y.; Das, A.; Lin, Z.; Cooper, I.B.; Rohatgi, A.; Wong, C.P. Hierarchical robust textured structures for large scale self-cleaning black silicon solar cells. Nano Energy 2014, 3, 127-133. [CrossRef]

22. Gangopadhyay, U.; Kim, K.; Dhungel, S.K.; Basu, P.K.; Yi, J. Low-cost texturization of large-area crystalline silicon solar cells using hydrazine mono-hydrate for industrial use. Renew. Energy 2006, 31, 1906-1915. [CrossRef]

23. Smith, A.W.; Rohatgi, A. Ray tracing analysis of the inverted pyramid texturing geometry for high efficiency silicon solar cells. Sol. Energy Mater. Sol. Cells 1993, 29, 37-49. [CrossRef]

24. Akila, B.S.; Vaithinathan, K.; Balaganapathi, T.; Vinoth, S.; Thilakan, P. Investigations on the correlation between surface texturing histogram and the spectral reflectance of (100) Crystalline Silicon Substrate textured using anisotropic etching. Sens. Actuators A Phys. 2017, 263, 445-450. [CrossRef]

25. Al-Husseini, A.M.; Lahlouh, B. Influence of pyramid size on reflectivity of silicon surfaces textured using an alkaline etchant. Bull. Mater. Sci. 2019, 42, 152. [CrossRef]

26. Zhang, Y.P.; Wang, W.T.; Wang, C.; Yang, J. Study of optical anti-reflection characteristics based on nanometer "pyramid" structure. Laser Infrared 2018, 48, 215-220. [CrossRef]

27. Lv, H.; Shen, H.; Ye, J.; Chao, G.; Han, Z.; Yuan, J. Porous-pyramids structured silicon surface with low reflectance over a broad band by electrochemical etching. Appl. Surf. Sci. 2012, 258, 5451-5454. [CrossRef]

28. Ou, H.-F.; Lin, Y.-K.; Hsueh, C.-H. Structural and optical properties of textured silicon substrates by three-step chemical etching. Langmuir 2021, 37, 9622-9629. [CrossRef] [PubMed]

29. Wang, P.; Liu, Z.; Xu, K.; Blackwood, D.J.; Hong, M.; Aberle, A.G.; Stangl, R.; Peters, I.M. Periodic upright nanopyramids for light management applications in ultrathin crystalline silicon solar cells. IEEE J. Photovolt. 2017, 7, 493-501. [CrossRef]

30. Lou, R.; Zhang, G.; Li, G.; Li, X.; Liu, Q.; Cheng, G. Design and fabrication of dual-scale broadband antireflective structures on metal surfaces by using nanosecond and femtosecond lasers. Micromachines 2020, 11, 20. [CrossRef] [PubMed]

31. Yoo, J.; Yu, G.; Yi, J. Black surface structures for crystalline silicon solar cells. Mater. Sci. Eng. B 2009, 159, 333-337. [CrossRef]

32. Chen, J.; Deng, T.; Wu, C.N.; Liu, Z.W. Fabrication of silicon nanopore arrays with three-step wet etching. ECS Trans. 2013, 52, 371. [CrossRef]

33. Munoz, D.; Carreras, P.; Escarre, J.; Ibarz, D.; Nicolas, S.M.D.; Voz, C.; Asensi, J.M.; Bertomeu, J. Optimization of KOH etching process to obtain textured substrates suitable for heterojunction solar cells fabricated by HWCVD. Thin Solid Films 2009, 517, 3578-3580. [CrossRef]

34. Choi, J.; Lee, T.S.; Jeong, D.S.; Lee, W.S.; Kim, I. Random Si nanopillars for broadband antireflection in crystalline silicon solar cells. J. Phys. D Appl. Phys. 2016, 49, 375108. [CrossRef]

35. Yi, H.; Yan, W.; Tan, X.; He, L. Study on silicon nanopillars with ultralow broadband reflectivity via maskless reactive ion etching at room temperature. Mater. Sci. Eng. B 2017, 223, 153-158. [CrossRef]

36. Chau, Y.-F.C.; Lin, C.-J.; Kao, T.S.; Wang, Y.-C.; Lim, C.M.; Kumara, N.; Chiang, H.-P. Enhanced photoluminescence of DCJTB with ordered Ag-SiO2 core-shell nanostructures via nanosphere lithography. Results Phys. 2020, 17, 103168. [CrossRef]

37. Chau, Y.F.C.; Chen, K.H.; Chiang, H.P.; Lim, C.M.; Huang, H.J.; Lai, C.H.; Kumara, N.T.R.N. Fabrication and characterization of a metallic-dielectric nanorod array by nanosphere lithography for plasmonic sensing application. Nanomaterials 2019, 9, 1691. [CrossRef]

38. Kim, J.; Yeo, C.; Lee, Y.; Ravindran, S.; Lee, Y. Broadband antireflective silicon nanostructures produced by spin-coated Ag nanoparticles. Nanoscale Res. Lett. 2014, 9, 54. [CrossRef] [PubMed]

39. Wang, Y.; Shao, B.; Zhang, Z.; Zhuge, L.; Wu, X.; Zhang, R. Broadband and omnidirectional antireflection of Si nanocone structures cladded by SiN film for Si thin film solar cells. Opt. Commun. 2014, 316, 37-41. [CrossRef]

40. Welch, C.C.; Goodyear, A.L.; Wahlbrink, T.; Lemme, M.C.; Mollenhauer, T. Silicon etch process options for micro- and nanotechnology using inductively coupled plasmas. Microelectron. Eng. 2006, 83, 1170-1173. [CrossRef]

41. Hung, Y., Jr.; Lee, S.-L.; Thibeault, B.J.; Coldren, L.A. Fabrication of highly ordered silicon nanowire arrays with controllable sidewall profiles for achieving low-surface reflection. IEEE J. Sel. Top. Quantum Electron. 2010, 17, 869-877. [CrossRef]

42. Chu, D.; Yao, P.; Huang, C. Anti-reflection silicon with self-cleaning processed by femtosecond laser. Opt. Laser Technol. 2021, 136, 106790. [CrossRef]

43. Leem, J.W.; Dudem, B.; Yu, J.S. Biomimetic nano/micro double-textured silicon with outstanding antireflective and superhydrophilic surfaces for high optical performance. RSC Adv. 2017, 7, 33757-33763. [CrossRef]

44. Kim, S.; Jeong, G.S.; Park, N.Y.; Choi, J.-Y. Omnidirectional and broadband antireflection effect with tapered silicon nanostructures fabricated with low-cost and large-area capable nanosphere lithography. Micromachines 2021, 12, 119. [CrossRef] [PubMed] 